\title{
Evaluation of Structuring and Equalization Policy Implementation of Civil Servant Teachers Public Senior High Schools (SMA) and Vocational Schools (SMK)) in Banda Aceh the Province of Aceh
}

\author{
Ismail $^{1}$, Ma'ruf Akabar ${ }^{2}$, Suparno Eko Widodo ${ }^{3}$ \\ \{ Ismail@gmail.com $\left.{ }^{1}\right\}$ \\ ${ }^{I}$ Doctoral Program, Education Management, Universitas Negeri Jakarta \\ Lecturers of Universitas Syiah Kuala Banda Aceh, Indonesia \\ ${ }^{2}$ Lecturer, Universitas Negeri Jakarta, Indonesia \\ ${ }^{3}$ Lecturer, Universitas Negeri Jakarta, Indonesia
}

\begin{abstract}
The purpose of this study is to evaluate the implementation of the policy of structuring and equalization of civil servant teachers in public SMA and SMK in Banda Aceh City. This research uses Stake's Countenance evaluation modelwhich consists of antecedent, transaction, and outcome. The results of this study indicate that the policy of structuring and equalization of teachers of public SMA and SMK in Banda Aceh has not been implemented in accordance with the expectations, which shows that there are advantages and disadvantages of teachers in almost every school on a particular subject, and these have impacts on the fulfillment of needs and the enhanchement of teachers' competence.
\end{abstract}

Keywords: Structuring and Equalization of Teachers, The Fulfillment of Teacher's Needs and Competence.

\section{Introduction}

The policy on structuring and equalization of civil servant teachers, which is stated in the Five Ministerial Joint Regulations, is based on considerations to ensure equal distribution of teachers between education units, between levels, between types of education, between districts/cities and/or between provinces in an effort to nationally realize the improvement and equalization of the quality of formal education as well as to support the achievement of national education objectives. In line with education policy, Scott Ellison (2012) states that education policies which absolve policy-makers and educational experts of accountability for student learning actually work to undermine their own normative justifications. Education policy should be accountable in improving the quality of education evenly. Furthermore [1] suggests that A policy theory consists of a set of statements that describe a particular policy, explain why, how, and under what conditions the policy effects occur, predict the outcomes of the policy, and specify the requirements necessary to bring about the desired policy effects. A policy is a series of statements that explain why, how, and what the impact of the policy is, and how to implement it. The regulations contain detailed policies which include;the obligations 
of the five ministries, authorities and responsibilities of provincial and district governments, monitoring and evaluation, guidance and supervision, funding, reporting, and sanctions.

In general, evaluating the implementation of policy on structuring and equalization of civil servant teachers is needed to assess the efficiency, effectiveness, and impact of the policies that have been implemented. Furthermore, [2] explains: Policy implementation refers to the mechanisms, resources, and relationships that link policies to programme action. More specifically it means to carry out, accomplish, fulfil, produce or complete a given task. Therefore, understanding the nature of policy implementation is important because international experience indicates that policies, once adopted, are not always implemented as envisioned and do not necessarily achieve the intended results. A policy in particular can be carried out when how to implement the policy is better understood; therefore, policy implementation is a complex processand even its implementation is not as envisaged and the result is not necessarily as expected. [3] explains thatAn evaluation policy is any rule or principle that a group or organization uses to guide its decisions and actions when doing evaluation. Every entity that engages in valuation, including government agencies, private businesses, and nonprofit organizations, has evaluation policies. Evaluation policy is the rule or principle used by groups or organizations to guide their decisions and actions when conducting an evaluation. Every activity involved in the assessment, including government agencies, private companies, and non-profit organizations, has an evaluation policy.The evaluation of the implementation of structuring and equalization policy of civil servant teachers of public SMA and SMK in Banda Acehhas never been done up to now, whereas the implementation of a policy requires an evaluation. On that basis, it is necessary to conduct a policy evaluation studyto see if the policy implementation reaches the established success criteria. The results of such evaluation can be utilized for decision making purposesin order to improve or increase the implementation of the policy in the future.

From the description above, a comprehensive review of the initial conditions of policy implementation, policy implementation process, as well as the results of the policy implementation of structuring and equalization of civil servant teachers of public SMA and SMK in Banda Aceh City is required. This study was conducted as a form of evaluation of policy implementation in supporting the improvement of education quality, especially the improvement of teachers' quality in public SMA and SMK in the Province of Aceh, especially in Banda Aceh.

\subsection{Objectives}

The general objective of this study is to know the implementation of structuring and equalization policy of civil servant teachers in public SMA and SMK in Banda Aceh. Using the Stake's Countenance evaluation model in particular, the research aimed to explain the implementation of policy in three phases namely: (1) Describing the antecedents of needs, policy goals, and policy foundations, as well as the readiness of institutions implementing policy of structuring and equalization of civil servant teachers at public SMA and SMK in Banda Aceh, (2) Explaining the implementation process (transaction) of the policy of structuring and equalization of civil servant teachers at public SMA and SMK in Banda Aceh, which includes: planning, organizing policy practitioners, mechanisms of activities implementation, and monitoring the implementation of policies, (3) Describing the outcomes to achieve from the implementation of policy of structuring and equalization and improving the performance and competence of civil servant teachersat public SMA and SMK in Banda Aceh. 


\subsection{Literature Review Definition Of Evaluation}

Evaluation is the process of determining the value for a thing or object which is based on certain references to specify a particular purpose. [4] suggests that evaluation comes from the word evaluation (English).The word is absorbed into the treasury of the Indonesian term with the aim of retaining the original word with a slight adjustment of Indonesian pronunciation to "evaluasi". The term "valuing" is the noun of "value".The definition of "measurement" refers to the activity of comparing things with certain units of measurement, so that its nature becomes quantitative. To understand further, the meaning of evaluation isa series of activities comparing the realization of inputs and outcomes towards plans and standards. Evaluation is an activity that assesses the results obtained during monitoring activities that take place. Evaluation also assesses the results or products that have been generated from a series of programs as a basis for making decisions about the level of success that has been achieved and the subsequent action required.

Evaluation as a process determines the outcomes that some activities have accomplished to support the achievement of goals. [4]suggest that the evaluation is activities to collect information about the operation of something, which then the information is used to determine the right alternative in making a decision. Evaluation by [5]is This definition centers on the root-term value and denotes that evaluation essentially involves judgment. While evaluation optimally employs objective procedures in order to obtain dependable and unbiased information. The statement has the meaning that evaluation is a process to determine the degree of behavioral changes that occur. The statement provides an understanding that in conducting an evaluation, there is a process that must be gone through systematically. Evaluation is done through the process of collecting and analyzing data for the purpose of making decision.

Evaluation by [6]is a process for describing an Evaluation and judging its merit and worth. Evaluation in this case is defined as an attempt to describe the characteristics to be evaluated. According to [7] the definition of evaluation is the determination of worth of athing. It includes obtaining information for use in judging the worth of program, product, procedure, or objective, or potential utility alternative approach designed to attain specified objectives. Evaluation is an activity to determine value, including information useful for the judgment of the existence of a program, products, procedures, and selecting potential strategy alternatives to achieve those goals. This opinion implies thatthere are certain criteria used to determine the value in the form of success criteria of a program, the process of implementation or the results achieved by a program. Furthermore, [8] says that evaluation is the pursuit of knowledge. About value. Evaluation is always a determination of merit and shortcoming. Essential function is the determination of merit. Evaluation is an attempt to pursue knowledge of value or something good that is considered valuable.In the implementation, the evaluation results can be used as information in making decisions on objects measured by certain dimensions.This is in accordance with [9] that evaluation of how the new worker in the office is coping may rely on informal observations of performance and the opinions of others, including the worker himself. From the above definition, it is implicitly seen that there are criteria used to determine the value and the existence of things assessed, as well as criteria.The intended criteria are the success criteria for program implementation and things assessed can be impacts or results achieved, or the procedure itself.There are two concepts contained in this statement, namely the effectiveness which is the ratio between its output and input,and the concept of efficiency that is the level of utilization of inputs that produce output through the process.

\subsection{Policy Evaluation}

A policy is an interpretation of the political priorities and principles of government in the 
form of programs and actions to provide the desired changes.A policy is meant to give signals to a particular society, but the signal is not complete yet.For example, "policy" may relate to the principles and priorities adopted by the governmentin relation to a problem, but the policy has not been translated into action. In this case, not all policies can explain how steps or efforts can lead to a change.In a different perspective, [10] presents an explanation of the following policy concepts.Policy is about choice: the choice of objectives; the choice of reasons for (in)action; the choice of policy instruments; the choice of how to respond to the consequences of policy outputs. These choices, their consequences and subsequent choices unfold in a temporal process in which uncertainty is a defining feature.Based on the above explanation, policy concerning choices which arechoice of objectives, choice of reasons for determining an action, choice of policy instruments, choice of how to respond to the consequences of policy output. These choices have consequences for the next option. This choice will continue to grow in a process, where uncertainty will be a key feature in making choices in a policy.In a later explanation, [10] suggests the meaning of choice and purpose contained in the following understanding: definitions of policy in terms of choice, or an action calculated to achieve a desired objective, or the purposeful connecting of ends with means are premised on a 'classical view' of policy as the result of a rational process: 'the model of policy making in the rationality project is a production model, where policy is created in a fairly ordered sequence of stages, almost as if on an assembly line.The definition of policy as an option or action is taken into account to achieve the desired objectives. Policy is the goal that leads to the end result, according to the classical view that policy is the result of a rational process. The policy-making model in process rationality refers to the production model, where policy is made in the order of activities like a series of processes.

\subsubsection{Evaluation Models}

A review of the various evaluation models is required to help the evaluator identify the conceptual basis in selecting the appropriate model. There are many approaches and models that can be used in policy evaluation. [11] in [12] suggests six evaluation models considered important namely: goal-attainment model, side-effects model, relevance model, client-oriented model, stakeholder model, collegial models (peer review, self-evaluation).Some other evaluation models are also widely used among others CIPP evaluation model, UCLA model, Brinkerhoff model (The Six-Stage), as well as Stake's Countenance model. The Countenance Evaluation Model was developed by [13]. This evaluation model explainsdescription and judgement are essential elements in programme evaluation. Evaluation with this model emphasizes on two activities namely descriptions and judgments as the core elements of evaluation. Further discussion of this model is presented in a separate description.

\subsubsection{Evaluation Model Used By Stake's Countenance}

The evaluation model used in this study is the Stake's Countenance Model developed by Robert E. Stake. This model is considered sufficient to assess a process of program implementation or policy implementation. [13] announces The countenance of a sound evaluation, he said, includes (1) description and judgment of a program; (2) data pertaining to the program's intended and observed antecedents, transactions, and outcomes; (3) the program's rationale; (4) analyses of congruence and contingencies; (5) identification of pertinent, often conflicting standards and judgments; (6) a variety of evaluation tasks and associated procedures; and (7) formative and summative uses of findings.

According to Stake, this evaluation model includes (1) program descriptions and ratings; (2) data relating to expectations and antecedent observations, transactions, and program outcomes; (3) program reasons; (4) congruence and contingency analysis; (5) identification of conflicting related matters and assessment standards; (6) various evaluation tasks and related procedures; and (7) using formative and summative findings.Stake (accessed 2016) identifies 
three phases in the evaluation ie. antecedents, transactions and outcomes. The antecedents phase refers to the initial conditions, transactions refer to the process of program intervention, and outcomes refer to the results achieved.

Furthermore [13] argues that Stake used antecedents, transactions, and outcomes as core concepts to structure his view of what should be done in describing and judging a program. He called for documenting a program's intents and observations - that is, its intended and observed antecedents, transactions, and outcomes.

Stake's evaluation model uses antecedents, transactions, and results as the core concept structurein his view of what should be done to explain and assess the program or policy. Assessment of core concepts is done through documentation of expectations (intents) and observations ie.expectations and observations about antecedents, transactions, and results.

Associated with the above three phases Stake (accessed 2016) presents the following explanation For operating the program, there will be many provisions or condition or contexts, each capable of being judged as to quality. I called these background conditions and inputs antecedents. Some are antecedents for which the program staff is responsible, some not. In many evaluations studies, we should gather data about intentions, the quality, and perceived of some of those antecedents.In operating the program or policy implementation, there will be many terms or conditions or contexts, each of which can be used to assess the quality of a program or policy. This is called a background condition and an antecedent input. Some antecedents of the program are responsible, but some are not.In many evaluation studies, data on the objectives, quality, and perceptions of some antecedents should be collected.

[13] argues We should gather similar cata about program activities, operations, functions, processes. I called transactions. Sometime the best data we can find are the data about the process. Sometimes we contract to carry out a "process evaluations". It may happen because the report is due before outcome data will be available. Or it may because the important thing for staff and stakeholders to be told is that program delivered. In evaluation practice the same data about program activities, operations, functions, and processes should be collected. This is called the transaction phase. Sometimes the best data to be found is data about the process. Sometimes "process evaluation" is done specifically. This may happen before the results data report is available. Or because it is important for the implementers and stakeholders to get information about the program being implemented.

Further [13]suggests that in the real world, the program delivered is not exactly the one promise. It had to be changed, and the changes may make it much better. We should evaluate theprogram that the organization now has in place, is quality to be discovered. The usual interest is in what is has accomplished, its impact, its outcomes. And usually we will thing and investing the greater share of evaluation budget in gathering outcome data. But often we will obtain many antecedent, transaction, an outcome.

In reality, the program or policy that is delivered is not always exactly like what is promised. This should be changed, and the change may be much better. Evaluation of programs owned by the organization is required to know the quality. The common interest in this regard is what has been achieved, impact, or outcomes.It usually takes more effort and budget than the evaluation budget in the process of collecting data on outcomes. But oftentimes there will be many things about antecedent, transaction and outcome.In this case [13] argues that the information required in this evaluation model includes rational, antecedent, transaction and outcome.Rationale shows background as well as the basic purpose of a program or policy. Antecedents, transactions and outcomes are equivalent to inputs, processes and products. Information is arranged in the form of a description and judgment matrix.To fill in the matrix, the evaluator may collect considerations from the users of the evaluation results. Data descriptions are classified into intent (expected destination) and observational circumstances. The judgment statement is classified in conditions that meet 
specific standards and specific judgmentson each element of the program or policy being evaluated.

In general, Stake's Countenance model can be described in the following matrix form

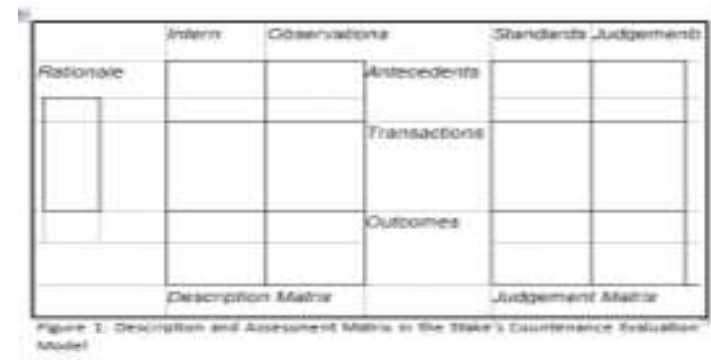

Furthermore [14] state that, The model proposed by Stake involves completing two data matrices: the so-called Description Matrix and Judgement Matrix. Each matrix is divided into two columns: intents and observations comprise the description matrix, and standards and judgement comprise the judgement matrix. Both matrices are divided into three rows, labeled from top to bottom, antecedents, transaction, and outcomes. The evaluation model proposed by Stake involves filling in two matrix data: the so-called matrix descriptions and assessment matrix. The description matrix consists of two categories: something that is planned (intents) and the result of observation (observation)which deals with what is done as desired from the first category. The categories of observations consist of:input (antecedents), processes (transactions), and results (outcomes). Evaluators make observations to obtain data about inputs (antecedents), processes (transactions), and results (outcomes).

Consideration matrix consist of standard categories and judgments categories as well as inputs, processes, and outcomes. Standard is a criterion that must be fulfilled by a program or policy implementation. Standards can be developed based on policy characteristics, and it can also be developed from other standards. The second category is the assessment, the evaluator makes an assessment of what has been done or what has been achieved.

According to [13] there are two principal ways of processing descriptive evaluation data: finding the contingencies among antecedents, transactions, and outcomes and finding the congruence between intents and observations. There are two main ways of processing descriptive evaluation data that is finding contingencies among antecedents, transactions, and results and finding the comformity between inten and observation that can be seen in the following figure:

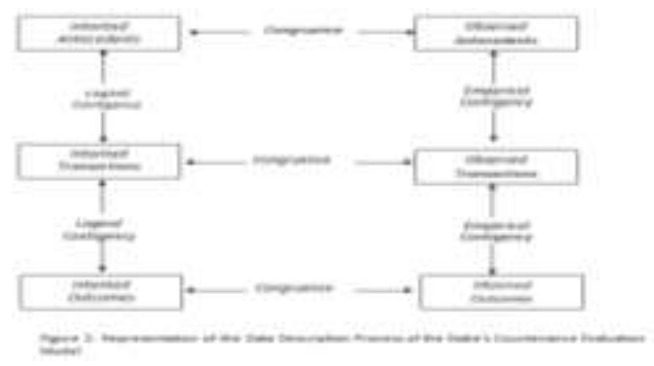

Stufflebeam and Coryn (1981) suggested Congruence analysis involves asking whether what was intended occurred. Were the observed antecedent conditions congruent with those that were expected? Did teachers carry out the directions of the curriculum guide? Were the 
intended outcomes achieved, and were there additional outcomes? Congruence analysis essentially is identical to Provus's recommendation (1971) that evaluators search for discrepancies between what was intended and what occurred.The congruence analysis involves the question whether what is expected happens. Are the observed antecedent conditions is in harmony with the expected ones?Is the program implemented as directed?Are the expected results achieved, and are there additional results? Conformity analysis leads the evaluator to find the difference between what is intended and what is happening.

\section{Research Methodology}

The study was conducted using evaluation method. The evaluation method is designed to make decisions about effectiveness, efficiency, and suitability of interventions and management of policy implementation that has been implemented. The use of evaluation methods in research on the implementation of policies on structuring and equalization of civil servant teachers is based on the understanding of Stufflebeam and Coryn (1981), who suggested that Policy evaluation uses a range of research methods to systematically investigate the effectiveness of policy interventions, implementation and processes, and to determine their merit, worth, or value in terms of improving the social and economic conditions of different stakeholders. Policy evaluation uses a variety of research methods that systematically examine the effectiveness of policy interventions, implementation and process, and determine performance, feasibility, or benefits in terms of improving the social and economic conditions of different stakeholders. The evaluation model used in this research is Stake's Countenance Evaluation Model.This model distinguishes three phases of policy evaluation, ie antecedents, transactions, and outcomes. Related to this research the antecendents phase describes the initial conditions of policy implementation that include: the background of need for teachers, policy objectives and targets, the foundation of the policy, and the readiness of institutions implementing the policy. The transactions phase will describe the execution process of policy implementation which includes:planning, organizing policy implementers, mechanisms of activities implementation, and monitoring the implementation of policies. Outcomes phase describes the results obtained through policy implementation that includes: the fulfillment of needs and equalization of teachers and the improvement of teacher performance and competence.

In general, the design of the Stake's Countenance Model evaluation used in this study is presented in the following figure:

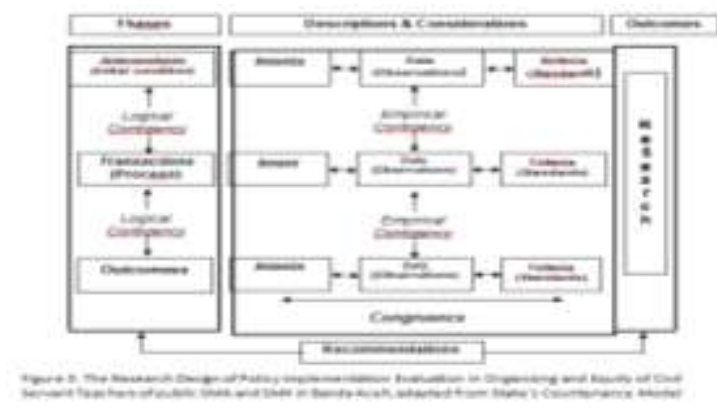

Based on evaluation design, Implementation of the Policy of Structuring and Equalization of civil servant teachers of public SMU and SMK in Banda Aceh City used the Stake's Countenance Model as presented in the Figure above. 


\section{Result and Discussion}

\subsection{Initial Condition Evaluation Result (Antecedents)}

The need for teachers is not evenly distributed and not yet well-suited as expected, whereas the needs of teachers is an absolute requirement for the implementation of education in schools. On that basis, the fulfillment of teacher availability both quantitatively and qualitatively is a major factor that must be metby every educational unit, and based on the need for teachers the government issued a policy of five ministers with expectations it is in accordance with the needs.

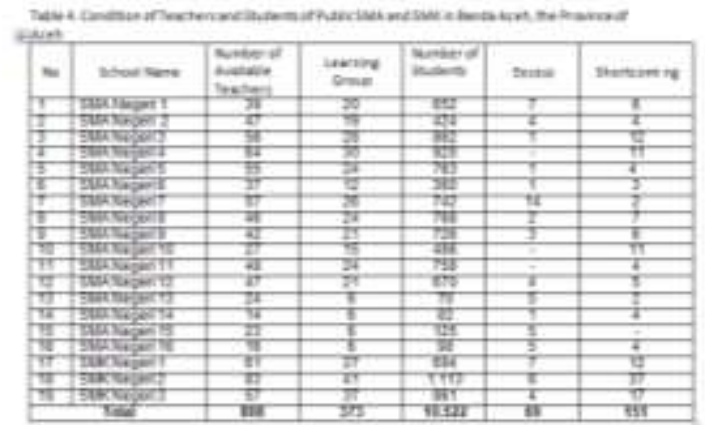

\subsection{Evaluation Result of Implementation Process (Transactions)}

\subsubsection{Policy Implementation Planning}

Planning in the Education Office of the province of Aceh is designed to determine the steps that need to be done by the facilitators of the policy before the policy implementation activities are carried out. Evaluation to policy implementation planning is conducted through an assessment to the planning of the activity program and the implementation of policy dissemination conducted by related agencies; in this case, planning by the Education Office of the province of Aceh is done at the level of Education Officearranged in the form of work program, at SMA and SMK section heads in the form of activity schedule, at the school level it is set forth in the form of needs analysis. The Education Office of the province of Aceh conducts socialization at the education office and at each public SMA and SMK of Banda Aceh in order to improve the understanding of the content of the policy of structuring and equity of tteachers although the achievement has not met the expected criteria due to the implementation which has not been maximized.

\subsubsection{Organizing Policy Facilitators}

In organizing, the Education Office and the schools create the structure to support the smooth implementation, to set, to classifyand to organize various clear and coordinated activities. The evaluation of organizing policy facilitators is done through assessing the organizational structure of policy facilitators and coordination among the competent elements of policy facilitators, policy executors at the The Education Office of the province of Acehlevel do not form a specific organizational structure. While the responsibility in the implementation ofstructuring and equlization of teachers of public SMA and SMK in Banda Banda Aceh isthe responsibilities of related Division Heads. In organizing, the facilitators are integrated in organization and work procedures of The Education Office of the province of Aceh,which is set forth in the organizational structure although not specifically formed, and coordination is done following the existing organizational structure in this case not 
specifically formed,the achievement level of the coordination process of the category in this case is still relatively low. The responsibility of the facilitators at the Education Office of the province of Acehis delegated to the related Division Heads. Vertical coordination is done among schools with Division Heads of SMA, SMK, GTK (Teachers or Education Personnel)andrelated Section Heads of the Education Office of the province of Aceh. Horizontal coordination is done among schools and coordination among schools and the Education Office of the province of Aceh.

\subsubsection{Mechanisms of Activity Implementation}

The mechanisms for implementing policy activities are well established for the sake of the policy implementation. Evaluation of documents on the mechanism of activity implementation is conducted through assessment of the analysis implementation of need for teachers according to the subjects in each public SMA and SMK of Banda Aceh, procedures for the activity implementation of structuring and equity policy of civil servant teachers. The results of the document analysis is still a constraint due to the excess and shortages of teachers at public SMA dan SMK in Banda Aceh.

\subsubsection{Monitoring of Policy Implementation}

Implementation of monitoring conducted by the Education Office of the province of Acehis based on structure and authority delegation. In this case the monitoring is only carried out by the supervisors of public SMA and SMK in Banda Aceh, which is intended to provide information about the causes and effects of a policy being implemented. Monitoring the implementation of the policy is done with the aim that the policy goes according to the desired expectations. Evaluation of monitoring is focused on the assessment of activities in the implementation of monitoring as well as assessing the course of the coaching and supervision process, which is done in the implementation of the teacher structuring and equalization policy. Monitoring activities are carried out by the Education Office of the province of Acehat public SMA and SMK in Banda Aceh, in this case the only assigned supervisors of the school and there has been no feedback on monitoring results to improve the policy process of teacher structuring and equalization. Coaching and supervision of policy implementation has not been properly programmed in this case the coaching has not been able to solve the problems faced in the implementation of the teacher structuring and equalization policy at public SMA and SMK Banda Aceh.

\subsection{Evaluation}

\subsubsection{The Fulfillment of the Needs and Equalization of Teachers}

The fulfillment of needs for teachers can be seen from teachers' workload which includes the calculation of needs based on the elaboration of the learning activities or face-to-face session per type of teachers per week, then divided by the number of face-to-face sessions i.e. 24 hours. Evaluation to the fulfillment of needs for teachers is seen based onthe fulfillment of the needs for teachers which has not evenly corresponded to the real needs in every public SMA and SMK in Banda Aceh,the province of Aceh.The implementation of the structuring and equilization policy of teachers has provided solutions to meet the needs for teachers, but has not been able to complete the fulfillment of needs for all subjects; this is due to the lack of teachers at public SMA dan SMK in Banda Acehdue to the absence of admission and recruitment of civil servant teachers in Aceh Province.

\subsubsection{The Improvement of Teachers' Competency}

At the Education Office of the province of Aceh, the increase in teachers' competency has not shown maximum results; it is shown from the UKG (Teachers' Competency Test) results 
that there are still many teachers of public SMA and SMK in Banda Aceh whose scores are below standard. From these results, the Education Office improves teachers' competency in the hope that it can meet the needs for teachers. The implementation of the structuring and equalization policy of civil servants teachers of public SMA and SMK in Banda Aceh of the province of Aceh is expected to have an impact on teachers' performance improvement, at least the improvement is able to give impact to the fulfilment of teaching hours load that has been set at least 24 hours per week. On that basis, the documentation evaluation on teachers' competency improvement is done through assessment that is expected to have the skills, experience, sincerity, competence, motivation and responsibility based on each subject. The Implementation of the structuring and equalization policy of teachers of public SMA and SMK in Banda Aceh has not had an optimal impact on the fulfilment of teacher working hours of at least 24 hours per week. This is because there are still a lot of teachers' workload that has not been met and these teachers belong to those with assessment of the low category. The same goes with the teachers' competency; the implementation of structuring and equalization policy of teachers has not given optimal impact on the improvement of teachers' competence through the fulfilment of workloads well as the fulfilment of academic qualifications. This is indicated by the low scores of UKG in Banda Aceh, the province of Aceh.

\subsection{Antencedents (Inial Conditions) of the Implementation of Structuring and Equalization Policy of Civil Servant Teachers of Public SMA and SMK in Banda Aceh.}

Evaluation to antecedent components (initial condition) of structuring and equaliazation policy of civil servant teachers at public SMA and SMK in Banda Aceh, the province of Aceh is done to four aspects namely: background of needs for teachers, policy objectives and targets, policy foundations, and readiness of policy-implementing institutions. Evaluation results show that the content of the policy has been in accordance with the facts about the background needs for teachers. The teacher structuring and equilization policy is in accordance with the initial conditions in the field, and is relevant to the facts about the excess/shortage of teachers and distribution of teachers who are not evenly distributed. The evaluation decision shows that the implementation of the structuring and equilization policy of civil servant teachers in public SMA and SMK in Banda Aceh of the province of Aceh needs to be done so that the availability of teachers meet the real needs on each subject at schools. Implementation of structuring and equilization policy of civil servant teachers is a means to meet the expectations of stakeholders for qualified education. According to [10], public policy is ultimately about achieving objectives. It is a means to an end. Policy is a course of action by governments designed to achieve certain results. The results to be achieved through the implementation, the policy of structuring, and equity of civil servant teachers are the fulfillment of the needs of teachers in each school in order to improve the quality of education.

Furthermore, in line with the evaluation results, [12] explains: public policies are considered to be any actions taken by governments that represent previously agreed responses to specified circumstances. Governments design public policies with the broad purpose of expanding the public good.The policy of structuring and equity of civil servant teachers can be seen as a government actionwhich represents a response to the condition of the teacher's shortcomings and uneven distribution of teachers. The government designed this policy with broad goals to develop and provide a good and beneficial impact for the improvement and equalization of the quality of education.

According to [15] the policy process begins with perception of a problem and ends with some sort of resolution or termination of the policy.The process of the birth of thestructuring and equilization policy of civil servant teachers began withperceptions of problems that the need for teachers has not been met and the distribution of teachers is not even. The decision of 
evaluation result that has been made indicates thatthis policy should still be implemented in public SMA and SMK in Banda Aceh of theprovince of Aceh, considering the shortage and excess of teachers has not been resolved.Further evaluation results show that policies have a clear goal and objective, namely to meet the needs for teachers in accordance with the real needs of every subject in the school evenly. Policy objectives and targets are known and understood by both the executing elements and the teachers. The accuracy and understanding of the policy objectives and targets have the potential to be a supporter of the implementationof structuring and equilization of civil servant teachers of public SMA and SMK in Banda Aceh of the province of Aceh. Based on the above opinion, the policy implementation is stages in the policy process in which the policy is enforced by a responsible bureaucracy. Thus, the implementation is a stage in the policy cycle in which there is a relationship between policy makers and policy targets, mediated by implementing institutions. The capacity of implementing institutions to carry out mediation needs to be supported by a number of resources including the duties and authorities of the policy executors themselves.

\subsection{Implementation Transactions (Process) of Structuring and Equalization Policy of Civil Servant Teachers of Public SMA and SMK in Banda Aceh}

Evaluation to the transaction component (process) of structuring and equilization policy of civil servant teachers at public SMA and SMK in Banda Aceh of the province of Aceh is carried out on four aspects of planning, organizing policy executors, mechanisms of activity implementation, and monitoring the implementation of policies. The evaluation results show that the planning has not been implemented optimally, not yet in accordance with the expected planning mechanism. The planning process has been initiated through socialization activities that have been implemented at every management level. However, planning for policy implementation is not done formally in the form of operational activities planning. Planning done tends to be spontaneous, only referring to the existing technical guidance.

The implementation of policy socialization should be tailored to the concept of stakeholder management as one of the themes in program or policy management.In [16] it is said that a stakeholder management plan, combined with the comunication plan, should deliver accurate, consitent, and timely information that reaches all relevant stakeholders as part of the communication prosess to facilitate a clear undertanding of the issues.Based on the above concept, stakeholder management planning in policy implementation should be combined with communication planning, providing accurate, consistent, and timely information so that it can reach all related parties as part of the communication process to facilitate a clear understanding of emerging issues. Viewed from the management in general, planning is the first step that must be done before an activity is implemented. According to [17] planning involves setting goals, establishing a strategy to pursue those goals, and forecasting future threats and opportunities that might influence the company's needs and strategies.Planning includes the efforts of setting goals, building strategies to achieve goals, making predictions of future threats and opportunities that may affect the needs and strategy of the organization.

In the execution, the implementation planning of structuring and equilization policy of civil servants teachers of public SMA and SMK in Banda Aceh of the province of Aceh is not done formally in the form of work programs. Planning is only done by following the stages specified in technical guidance. The planning process is done by the Education Office of the province of Acehby delivering instructions to Division Heads and Section Heads to develop an analysis of the needs for teachers, the excess and shortage of teachers.

Based on the evaluation on the aspect of the executors' organizing, it is seen that the implementation of structuring and equity policy of teachers has been implemented in a structured manner involving the central government, provincial government, district/city government, and education unit. The authority and duties of each partyhave been strictly 
regulated in the Five Ministerial Joint Regulations as well as in technical guidelines.

Organizing the executors of the structuring and equalization policy of teachers is integrated in the organization and working procedures of the Education Office of the province of Aceh.Its implementation does not create an organizational structure that deals specifically in implementing the structuring and equalization policy of the teachers. However, this is quite effective because the availability of organizational structure supports the implementation of coordination between elements, which is related to the implementation of the structuring and structuring policy of civil servant teachers of public SMA and SMK in Banda Aceh of the province of Aceh. Furthermore, according to [18] organizing involves assigning tasks, grouping tasks into departments, delegating authority, and allocating resources across the organization.Accordingly, organizational implementation of the policy has been done throughjob assignments, grouping tasks at each level of managementstarting from the Education Office, Division Heads of SMA, Division Heads of SMK, Division Heads of GTK, related Section Heads and up to schools. In organizing, the mechanism of delegating authority and allocation of resources to all parts of the organization takes place. This condition will be more easily realized by using the existing organizational structurein the environment of the Education Office of the province of Aceh. Evaluation results on the mechanism of the activities implementation show that the implementation of the structuring and equity policy of civil servants teachers of public SMA and SMK in Banda Aceh has been implemented by following the technical guidance available. The implementation process implements the teacher structuring and equilization policyby coordinating among the studied levels in the implementation of the policy in accordance with their respective authorities.

\subsection{Implementation Outcomes (Results) of Structuring and Equalization Policy of Civil Servants Teachers of Public SMA and SMK in Banda Aceh}

Evaluation on the components of implementation outcomes (results) of structuring and equalization policy of civil servants teachers of public SMA and SMK in Banda Aceh is carried out toward two aspects, namely the aspect of the fulfillmet of needs for teachers and teachers equilizationas well as that of teachers' performance and competency improvement.Based on the evaluation to the fulfillment of needs for teachers and equilization of teachers of public SMA and SMK in Banda Aceh,it appears that the implementation of the policy has given results. Although the results are not maximized as expected, it has shown the fulfillment of needs for teachers both in quality and quantity. Through data collection and redistribution, the shortcoming and excess of teachers cannot be overcome thoroughly. The implementation of this policy has provided solutions to meet the needs for teachers. Nevertheless, it has not yet completely resolved the problem of teacher's shortcoming and excess. There are still some schools experience the excess and shortage of teachers in almost every subject. The expectation from outcomes of structuring and equilization policy of teachers of public SMA and SMK in Banda Aceh of the province of Acehis that it can improve the competence and performance of teachers better, although the implementation of structuring andequalization policy of teachers is only able to overcome the problem of the shortage of teaching hours that must be carried out by the teachers. According to Stake (2004),in the real world, the program delivered is not exactly the one promise. It had to be changed, and the changes may make it much better. In the real condition, the program or policy delivered is not always the same as what is expected or promised. This should be changed, and the change should be much better. The implementation of structuring and equilization policy of teachers evidently does not directly improve the competence or performance of teachers.

Based on the above description, the results of this study show empirical evidence that preliminary conditions of a policy do not guarantee the success of the policy without the 
support of a good implementation process.Outcomes or results that are not optimal can be caused byweaknesses in the implementation process of structuring and equilization policy of civil servant teachers. The facts show that the implementation of the structuring and equilization policy of teachers at public SMA and SMK in Banda Acehhas been supported by a good initial condition(antecedent). However, the implementation process (transaction) that includes planning, mechanism of activities implementation, and implementation monitoring has not been implemented optimally. Therefore, the results achieved have not met the expectations.

\section{Conclusions}

The results of Antecedent Evaluation namely the initial condition of thestructuring and equilization policy of civil servant teachers of public SMA and SMK in Banda Aceh, the province of Aceh is in accordance with the expected conditions. This is shown by: (1) the policy content which is relevant with the background needsas well as the unequal distribution of teachers at each public SMA and SMK in Banda Aceh City; (2) the policy has the right goals and targets; (3) the policy has a legal foundation in accordance with the Laws, Government Regulations, Ministerial Regulations, and Regional Regulations, which have been established previously; (4) the Education Office of the province of Aceh has adequate human resources readiness,clear and integrated task structures, and the availability of facilities and budget that can be utilized optimally. The results of TransactionEvaluation, namely the implementation process of the structuring and equilization policy of civil servant teachers of public SMA and SMK in Banda Aceh City of the province of Aceh is not as it should be. This is shown by: (1) the planning process that has not been formally formulated in the form of activity programsand the achievement of socialization result that has not been optimal; (2) the implementing element is not organized in a specific structure but it can be well coordinated; (3) the mechanism of activitiy implementation that has not been optimal, only some parts of the activities carried out according to procedures in technical guidances; (4) monitoring is not yet optimally carried out, only done by the school superintendents; no special teams formed by the Education Office of the province of Aceh, and no monitoring results can be yet utilized in improving the policy implementation process, and guidance and supervision have not been done programmatically. The results of the OutcomeEvaluation,namely policy implementation, has not yet given impacts as expected. This is shown by: (1) policy results only have an impact on work performance improvement through the fulfillment of teachers' workload although it has not included all teachers of the field of study, and has not had an impact oncompetence/qualification improvement of teachers and the quality of education; (2) the implementation results of the structuring and equilization policy of civil servants teachers of public SMA and SMK in Banda Aceh of the province of Aceh has not been able to overcome the problems of the excess and shortages of teachers evenly for each subject at each school.

\section{Recommendation}

The central government should be more directed in order to be able to give a real impact on the fulfillment of the needs for teachers according to the real needs of each school. In addition, the policy set should be able to be a solutionover the condition of teacher excess and shortcoming and uneven distribution of teachers. The Education Office of the province of Acehis expected to increase the intensity of coaching and supervisionthrough monitoring and 
evaluation activities to the implementation of technical policy implementation. Monitoring and evaluation process can be done by empowering school inspectors through the delivery of special tasksor by forming the Monev Team who are specifically tasked with monitoring activities related to the implementation ofthe structuring and equilization policy of civil servant teachers at each public SMA and SMK. As a supporting device, an instrument for clear monitoring and evaluation should be established. The school principal is expected to be able to arrange activity planning earlier before the new school year beginsto avoid delays in the process of meeting the needs for teachers. The principals of public SMA and SMK in Banda Acehcan make an analysis of need for teachers on a quarterly basis in monthly reports and periodic reports in every academic year, and then submit it to the Education Office of the province of Aceh. Related to planning, the principals need to coordinate among schools when they will transfer and/or give assignments to teachers at other schools such as finding an extra hour at another school.

\section{References}

[1] G. Sharpe, "A Review of Program Theory and Theory-Based Evaluations," Am. Int. J. Contemp. Res., vol. 1, no. 3, pp. 72-75, 2011.

[2] R. M. Mthethwa, "Critical dimensions for policy implementation," African J. Public Aff., vol. 5, no. 2, pp. 36-47, 2012.

[3] W. Torchim, "Evaluation Policy and Evaluation Practice," New Dir. Eval., vol. 123, no. 114, pp. 13-32, 2009.

[4] S. Arikunto and C. S. Abdullah, Evaluasi Program Pendidikan, Pedoman Teoritis bagi Mahasiswa dan Praktisi Pendidikan. Jakarta: Bumi Aksara, 2004

[5] Stufflebeam, Systematic evaluation. Boston: Kluwer Nijhoff Publishing, 1985.

[6] E. G. Guba and Y. S. Lincoln, Effective Evaluation: Improving the Usefulness of Evaluation Results through Responsive and Naturalistic Approaches. San Fransisco: Jossey Bass Pub, 1985.

[7] B. R. Worthten and J. R. Sanders, Educational evaluation: Theory and practice. Ohio: Charles A. Jones Publishing Company, 1981.

[8] R. E. Stake, Standards-Based \& Responsive Evaluation. Thousands Oaks-London New Delhi: SagePublications, 2004

[9] J. M. Owen, Program Evaluation, Formand Approach. Sydney: Allen \& Unwin PtyLtd, 2006.

[10] A. Kay, The Dynamics of Public Policy Theory and Evidence. Massachusetts: Edward Elgar Publishing, Inc, 2006.

[11] E. Vedung, Public Policy and Program Evaluation. New Jersey: Transaction Publisher, 2009.

[12] E. Araral, S. Fritzen, M. Howlett, M. Ramesh, and X. Wu, Routledge Handbook of Public Policy. New York: Routledge, 2013.

[13] R. E. Stake, "The countenance evaluation model," 1967.

[14] E. G. Guba and Y. S. Lincoln, Effective Evaluation: Improving the Usefulness of Evaluation Results through Responsive and Naturalistic Approaches. San Fransisco: Jossey Bass Pub, 1981.

[15] K. B. Smith and C. W. Larimer, The Public Policy Theory Primer. Central Avenue, Boulder: Westview Press, 2009.

[16] Project Management Institute, The Standard for Program Management. Pennsylvania: Project Management Institute, Inc., 2006.

[17] J. Philips and S. M. Gully, Organizational Behavior: Tools for Success. Mason: Cengage Learning, 2011.

[18] R. L. Daft, New Era of Management. New Jerseys: Prentice Hall, 2012. 